\title{
A Modified Energy-Based Approach for Fatigue Life Prediction of Superelastic NiTi in Presence of Tensile Mean Strain and Stress
}

\author{
M.J. Mahtabi ${ }^{1}$ and Nima Shamsaei ${ }^{2, *}($ Corresponding Author) \\ ${ }^{1}$ Department of Mechanical Engineering, Mississippi State University, MS 39762, USA \\ ${ }^{1}$ Center for Advanced Vehicular Systems (CAVS), Mississippi State University, MS 39762, \\ USA \\ ${ }^{2}$ Department of Mechanical Engineering, Auburn University, Auburn, AL 36849, USA \\ *Corresponding author \\ Tel: (334) 844-4820 \\ Email: shamsaei@auburn.edu
}

\begin{abstract}
Submitted to:
International Journal of Mechanical Sciences
\end{abstract}

Revised version submission: July 2016

Original submission: April 2016 


\begin{abstract}
Fatigue behavior of superelastic NiTi (i.e. Nitinol) is experimentally investigated and an energy-based fatigue model is proposed to account for the effects of tensile mean strain and stress on fatigue resistance. Several zero and nonzero mean strain tests at various strain amplitudes were conducted on cylindrical fatigue specimens with uniform gage sections. Experimental results revealed significant detrimental effects of the tensile mean stress on the fatigue life of the superelastic NiTi. On the stress plateau, where a change in the mean strain did not significantly influence the stress value, fatigue lives were observed to be similar. A modified energy-based model is proposed to account for the effects of mean stress and strain on the fatigue behavior of superelastic NiTi. Among all the models investigated in this study, the proposed energy approach was able to better correlate the fatigue data with and without mean strains/stresses.
\end{abstract}

Keywords: Fatigue damage; Mean stress; Energy method; Shape memory alloy; Life prediction; Review 


\section{Nomenclature}

$2 N_{f}$

$\mathrm{A} \rightarrow \mathrm{M}$

$b$

$c$

$E_{A}$

EFRSA

$E_{M}$

$\mathrm{HCF}$

$\mathrm{LCF}$

$\mathrm{M} \rightarrow \mathrm{A}$

$N_{e q, M}$

$N_{f}$

$R_{\varepsilon}$

$R_{\sigma}$

$\varepsilon_{a}$

$\varepsilon_{\max }$

$\varepsilon_{\min }$

$\varepsilon_{f}^{\prime}$

$\varepsilon f A M$

$\varepsilon s A M$

$\sigma_{a}$

$\sigma_{e}$

$\sigma_{e q, M}$

$\sigma_{m}$

$\sigma_{\max }$

$\sigma_{\min }$

$\sigma_{f}^{\prime}$

$\sigma s A M$ number of reversals to failure

austenite to martensite transformation

fatigue strength exponent

fatigue ductility/superelasticity exponent

austenite modulus

Equivalent Fully Reversed $\underline{\text { Stress }} \underline{\text { Amplitude }}$

stress-induced martensite modulus

high-cycle fatigue

low-cycle fatigue

martensite to austenite transformation

equivalent fully reversed number of cycles to failure

experimental number of cycles to failure

strain ratio in a cyclic loading $\left(\varepsilon_{\min } / \varepsilon_{\max }\right)$

stress ratio in a cyclic loading $\left(\sigma_{\min } / \sigma_{\max }\right)$

strain amplitude

maximum strain

minimum strain

fatigue ductility/superelasticity coefficient

$\mathrm{A} \rightarrow \mathrm{M}$ finish strain

$\mathrm{A} \rightarrow \mathrm{M}$ start strain

stress amplitude (i.e. alternating stress)

fatigue stress limit (fatigue endurance stress)

equivalent fully reversed stress

mean stress

maximum stress

minimum stress

fatigue strength coefficient

$\mathrm{A} \rightarrow \mathrm{M}$ start stress (i.e. start of loading plateau stress) 
ultimate stress 


\section{1- Introduction}

NiTi (also known as Nitinol), an almost equiatomic alloy of nickel and titanium, has gained significant popularity in several applications due to its unique properties such as superelasticity and shape memory effects, as well as high resistance to severe environmental conditions. In civil engineering applications, NiTi alloys have been used as energy dissipation tools in bridges and earthquake resistant structures [1]. NiTi has also been employed widely as actuators in automotive [2] and aerospace [3] industries. In particular, superelastic NiTi is used as a biomaterial for many devices such as endovascular stents, vena cava filters, endodontic files and implants, where a combination of biocompatibility, strength, deformation tolerance and fatigue resistance is needed.

In many applications, NiTi components are under cyclic loading which makes them prone to fatigue failure. Accordingly, fatigue of NiTi has been studied and more complexities as compared to other metals have been reported [4,5]. The complex behavior arises from several phase transformations in NiTi under thermal and/or mechanical loading. Pelton et al. [6] conducted a large number of uniaxial fatigue tests on superelastic NiTi using the standard rotating bending fatigue test setup [7] and reported a multi-linear strain-life (i.e. $\varepsilon-N$ ) behavior in the log-log scale. They reported less sensitivity of the fatigue life to the strain amplitudes on the stress plateau, where strain amplitude falls between austenite to martensite start and finish strains, i.e. $\varepsilon s A M<\varepsilon a<\varepsilon f A M$. Mahtabi et al. [4] explained such a behavior to be related to the almost constant stress amplitude acting on the specimen on the plateau, and thus, concluded stress to be a more influential parameter than strain on the fatigue behavior of superelastic NiTi. 
NiTi components may also experience some constant loading in addition to the cyclic one in certain applications. For instance, NiTi stents are under a nonzero mean strain cyclic deformation at a frequency of human's heartbeat, i.e. $\sim 1 \mathrm{~Hz}$. There is an almost constant load together with a cyclic load acting on these components as the heart pumps the blood into the vessel. It should be mentioned that mean stresses/strains can also appear in a component as a result of residual stresses due to the manufacturing and/or post-manufacturing processes. In addition, superelastic NiTi exhibits a higher stress plateau in compression than in tension that results in an asymmetric tension-compression deformation response. Under strain-controlled tests, when the strain amplitude is larger than $\mathrm{A} \rightarrow \mathrm{M}$ start strain, $\varepsilon s A M$, there is a compressive mean stress acting on the material, and thus, a fully reversed strain-controlled test is indeed a nonzero mean stress test.

Mean strain is known to be ineffective on the fatigue resistance unless it results in some mean stress during cyclic loading. For superelastic NiTi, however, the mean stress in nonzero mean strain tests appears not to relax much. Several studies, therefore, have considered the effects of mean strain and stress on fatigue behavior of superelastic NiTi. Tolomeo et al. [8] and Pelton et al. [9] studied the fatigue behavior of NiTi diamond-shaped components under displacementcontrolled condition. The finite element analyses conducted in their studies illustrated existence of mean strains/stresses at the critical location of the component. Based on the finite element simulations together with experimental results, constant-life diagrams were generated for a certain run-out life (e.g., $N_{f}=10^{6}$ or $10^{7}$ cycles). These diagrams revealed some beneficial effects of tensile mean strain on the fatigue behavior of superelastic NiTi, where the mean strain was between martensite start and finish strains, i.e. $\varepsilon s A M$ and $\varepsilon f A M$. More specifically, both studies reported larger tolerable strain amplitudes at run-out for mean strains around 3\% as 
compared to, for example, $1 \%$ mean strain, indicating a higher fatigue resistance in presence of a larger tensile mean strain. Beneficial effects of tensile mean strains were also reported by Morgan and co-workers [10], who conducted strain-controlled fatigue tests on straight wire specimens at $2 \%, 4 \%$ and $6 \%$ tensile mean strains and strain amplitudes of $0.5-3.0 \%$. They reported longer fatigue lives for superelastic NiTi by an increase in tensile mean strain. Based on their results, the effect of tensile mean strain was more pronounced in high-cycle fatigue (HCF) regime and almost no effect was reported in low-cycle fatigue (LCF) regime, indicating less sensitivity of the fatigue resistance to mean strain in LCF, as typically observed for most metallic materials. This observation becomes even more interesting knowing that superelastic NiTi does not exhibit any plastic deformation, and most likely not much mean stress relaxation, in the investigated strain range.

Mean stress effect on the fatigue behavior of superelastic NiTi was also studied by Moumni et al. [11]. They conducted several force-controlled fatigue tests on superelastic NiTi with different stress ratios $\left(R_{\sigma}\right)$ and reported significantly shorter fatigue lives for specimens under tensile mean stress conditions. Results from Moumni et al. [11] indicate the high sensitivity of superelastic NiTi to tensile mean stress.

Due to the presence of mean strains in many applications of superelastic NiTi, there is a critical need for experimental and analytical research on the effects of mean strain/stress on the fatigue behavior of this alloy. Such an understanding is also required for fatigue life analysis of NiTi alloys under variable amplitude and/or multiaxial [12] loadings, as more realistic loading conditions for many components and structures. Moreover, due to the lack of comprehensive experimental data, there is not a robust model in the literature for the effects of mean strain/stress on the fatigue behavior of NiTi. In this study, nonzero mean strain fatigue experiments are 
conducted on superelastic NiTi and several mean stress correction models are evaluated to explain the effects of mean stress/strain on uniaxial fatigue behavior of this material.

\section{2- Material and Experimental Setup}

Straight bars of $\mathrm{Ni}_{50.8} \mathrm{Ti}_{49.2}$ (atomic \%) composition were machined to cylindrical fatigue specimens with uniform gage section. Specimens had a $10 \mathrm{~mm}$ diameter at the grip section and a $7 \mathrm{~mm}$ diameter at the gage section to minimize the possibility of failure outside the gage section. Designed geometry and an image of a fatigue specimen are shown in Fig. 1. The specimen geometry for strain-controlled testing is designed to facilitate testing and prevent buckling in fully reversed fatigue tests at large strain amplitudes. As a result, the geometry and dimension of the specimens do not completely fulfil the requirements of ASTM standard [13]. Surface of the specimens were mechanically polished to a very fine level, equivalent to grit $\# 4000$, to reduce the possibility of cracks initiating from the machining marks on the surface. A heat treatment, including short annealing followed by quenching in iced water, was conducted on the machined specimens. This rapid cooling step provided superelastic NiTi specimens at room temperature. It is worth mentioning that the heat treatment was selected based on the recommendations made by Pelton et al. [14] and some trial-and-error to determine the suitable time and temperature.

Both monotonic and cyclic tests were carried out at room temperature $\left(\sim 24{ }^{\circ} \mathrm{C}\right)$. Tensile properties of the material was determined based on two strain-controlled tensile tests using Instron 5882 electro-mechanical machine at a strain rate of $10^{-3} \mathrm{~s}^{-1}$ up to $6.5 \%$ strain. Straincontrolled cyclic tests were conducted using an MTS 810 servo-hydraulic fatigue machine at various strain amplitudes (i.e. $\varepsilon_{a}=0.4 \%, 0.5 \%, 1 \%, 1.1 \%, 1.25 \%$ and $1.5 \%$ ) and three different strain ratios $\left(R_{\varepsilon}=\varepsilon_{\min } / \varepsilon_{\max }\right)$, including fully reversed $\left(R_{\varepsilon}=-1\right)$, pulsating $\left(R_{\varepsilon}=0\right)$, and tensiontension $\left(R_{\varepsilon}=0.5\right)$. The considered large mean strains in this study were to simulate the loading 
condition in some applications, such as self-expanding NiTi stents, where a large mean strain is applied in addition to the cyclic strain [15]. An MTS uniaxial extensometer with a $15 \mathrm{~mm}$ gage length was used to measure and control the strain during fatigue tests. In order to protect the surface of the specimen, multiple layers of clear tape were placed on the gage section where the extensometer's knife edges were touching it. Different frequencies for different strain ranges were used to obtain a nearly constant average strain rate of $0.1 \mathrm{~s}^{-1}$ for all the cyclic tests.

\section{3- Experimental Results}

\section{3-1- Monotonic Behavior}

Stress-strain responses of the material, obtained from two monotonic tensile tests, are presented in Fig. 2 and the average tensile properties are listed in Table 1. It should be mentioned that all the stress and strain values in this study are engineering values calculated based on the initial geometry of the specimens. As can be seen from this figure, this NiTi alloy has a starting modulus (i.e. austenite modulus, $E_{A}$ ) of around $73 \mathrm{GPa}$. A stress plateau of $\sim 500$ $\mathrm{MPa}$, starting at a strain level of $\sim 1 \%$, where the material starts transforming from austenite to martensite $(\mathrm{A} \rightarrow \mathrm{M})$, can be clearly noticed in Fig. 2. As a result of stress-induced phase transformation, the stress plateau continues up to $\varepsilon=3.4 \%$, where the material becomes fully martensitic. Beyond this strain level, there is a linear relation between stress and strain variations with a lower modulus (i.e. stress-induced martensite modulus, $E_{M}$ ) of $22 \mathrm{GPa}$.

\section{3-2- Cyclic Behavior}

Cyclic behavior of superelastic NiTi with and without mean strains as well as the corresponding properties were previously reported and discussed in [16]. Initial reductions in $\mathrm{A} \rightarrow \mathrm{M}$ start stress and the area enclosed by the hysteresis loop under cyclic loads were observed

for this superelastic NiTi [16]. However, the material response was found to reach a stable state after a limited number of cycles, similar to the observations by Miyazaki et al. [17]. 
Furthermore, a significantly higher plateau stress in compression than in tension was observed [16]. Such asymmetry in stress response, and therefore, the resulted compressive mean stress where $\varepsilon_{a}>\varepsilon S A M$ may be beneficial to the fatigue life of superelastic NiTi under fully reversed strain-controlled conditions. Unstraining from a strain level on the stress plateau was observed to occur at a slope between the austenite modulus $\left(E_{A}\right)$ and the stress-induced martensite modulus $\left(E_{M}\right)$ [16], which was also in agreement with other studies [18]. Moreover, an initial cyclic hardening behavior together with mean stress relaxation was noticed for the superelastic NiTi in strain-controlled cyclic tests [16].

Details of different fatigue tests are presented in Table 2 and strain-life data from straincontrolled fatigue experiments are presented in Fig. 3. The arrow in this figure indicates grip failure, implying a longer fatigue life for the specimen. The observed fatigue life for the specimen with grip failure, which corresponds to the material in austenitic region, indicates a significant increase in the fatigue life when the maximum strain is smaller than the $\mathrm{A} \rightarrow \mathrm{M}$ start strain (i.e. $\varepsilon_{\max }<\varepsilon S A M$ ). The abrupt reduction in the fatigue life for strain amplitudes larger than $E S A M$ may be attributed to the detrimental effects of stress-induced phase transformation on the fatigue behavior of this material. Studies $[6,19]$ have shown that the fatigue response of superelastic NiTi may be presented better by a bilinear/multilinear relation, which differentiates between the high- and mid-cycle fatigue regimes. Thus, the test that failed at the grip may belong to the high-cycle regime, which does not follow the same trend as the other test data. As seen in Fig. 3 for a constant strain amplitude, shorter fatigue lives are expected for specimens with larger tensile mean strains, indicating a high sensitivity of the fatigue life of superelastic NiTi to tensile mean stress. Moreover, the strain-life fatigue data for a constant $R_{\varepsilon}=\varepsilon_{\min } / \varepsilon_{\max }$ can be expressed by a linear relationship in a $\log -\log$ plot, indicating a power-law relation between 
strain amplitude and number of reversals to failure, $2 N_{f}$, for the life regimes investigated in this study. However, this linear relation only exists up to the run-out strain level for the fully reversed test condition $\left(R_{\varepsilon}=-1\right)$.

\section{4- Fatigue Analysis and Modeling}

In this section, mean stress correction models are briefly reviewed and their applicability in correlating zero and nonzero mean stress fatigue data for superelastic NiTi is evaluated. Analyses are conducted in stress-life and strain-life methods as well as energy approaches.

\section{4-1- Stress-Life Analysis}

Stress-based mean stress correction models, such as Goodman [20], basically provide an approximation of an equivalent fully reversed stress amplitude (EFRSA) that yields similar effects on fatigue life as compared to those resulted from a combination of both mean stress and stress amplitude. The general procedure to employ these models is to calculate the EFRSA for each test and plot them against experimentally observed fatigue lives of specimens. The prediction line for each model can be approximated as a power-law equation with a general form as Eq. (1):

$\sigma e q=\sigma f^{\prime} 2 N f b$

where $\sigma_{e q}$ is the EFRSA, $N_{f}$ is the number of cycles to failure and $2 N_{f}$ is the number of reversals to failure. $\sigma_{f}^{\prime}$ and $b$ are fatigue strength coefficient and exponent, respectively, which are derived based on the fully reversed force-controlled test data (i.e. $\sigma_{m}=0$ ). In other words, the fully reversed test data are used as the base-line and the fit to this set of data is considered as the prediction line. The attempt is then to shift the nonzero mean stress test data on the stress axis toward the prediction line by finding an appropriate EFRSA. A comprehensive discussion on the effects of mean stress on fatigue behavior of metallic materials can be found in [21]. 
Generating an appropriate set of fatigue parameters (i.e. $\sigma f^{\prime}$ and $b$ ) for the stress-life analysis requires a set of experimental data under fully reversed force (stress)-controlled condition, which was not available in this study. Therefore, the fatigue coefficient and exponent for the prediction line are calculated from fully reversed strain-controlled fatigue tests, where there may exist a compressive mean stress as a result of asymmetry in the stress-strain response of the material. Subsequently, the estimated fatigue parameters (i.e. $\sigma f^{\prime}$ and $b$ ) in this study may not be the most accurate ones.

For each strain-controlled test, maximum and minimum stresses, and subsequently, mean stress and stress amplitude, were determined based on the stress-strain response (i.e. hysteresis loop) of the material near the mid-life. It is worth mentioning that the stress-strain response of the superelastic NiTi reaches a stable condition after a limited number $(\sim 100-200)$ of cycles $[16,17,22]$. Thus, the mid-life stress response of the material can be fairly accurately considered as the stable stress response. In order to calculate the prediction line in absence of fully reversed force-controlled tests, the stress amplitude versus the number of reversals to failure for all the fully reversed strain-controlled tests was plotted in semi-log scale, as presented in Fig. 4. A

power function in the form of Eq. (1) was fitted to the data and then used to determine $\sigma f^{\prime}$ and

$b$. It should be noted again that in all the stress-life analyses for mean stress correction in this study, the horizontal axis is the experimentally observed number of reversals to failure, $2 N_{f}$, and the vertical axis is the EFRSA, which varies according to the employed mean stress correction model.

\section{Goodman Model}

Goodman relation is presented by a constant-life diagram for different combinations of mean stress and stress amplitude that result in a certain fatigue life, $N_{f}$, and is expressed as: 
$\sigma a \sigma e+\sigma m \sigma u=1$

where $\sigma_{a}$ and $\sigma_{m}$ are stress amplitude and mean stress, respectively. $\sigma_{u}$ is the ultimate tensile stress of the material and $\sigma_{e}$ is the fatigue limit (i.e. endurance limit) for a certain "run-out" life in a fully reversed force-controlled test. This equation determines combinations of mean stress and stress amplitude under which the material has the same life as the $\sigma_{e}$ in fully reversed condition. In cases where samples fail in lives shorter than the "run-out" life, an equivalent fatigue strength, $\sigma_{e q, G}$ (where subscript $\mathrm{G}$ indicates Goodman relation), should be calculated using the following equation:

$\sigma e q, G=\sigma a 1-\sigma m / \sigma u$

This equivalent stress should then be combined with the fatigue life prediction equation (i.e. Eq. (1)) from fully reversed data to calculate the fatigue life that accounts for mean stress effects.

\section{SWT Model}

The original Smith-Watson-Topper (SWT) damage model [23] is a strain-stress-based parameter that considers the effects of mean stress on fatigue behavior. For stress-life analysis, SWT equivalent fully reversed stress, $\sigma_{e q, S W T}$ is calculated using the following equation [21] based on the stress amplitude, $\sigma_{a}$, and maximum stress, $\sigma_{\max }$ :

$\sigma e q, S W T=\sigma a \sigma \max$

This equivalent stress was used to calculate the predicted fatigue life, using SWT model, along with equation Eq. (1).

\section{Walker Model}

The Walker damage parameter [24] can be considered as the general form of the SWT model that adjusts the contribution of maximum stress and stress amplitude to the fatigue damage. For 
stress-life analysis purposes, the Walker equivalent fully reversed stress, $\sigma_{e q, W}$ can be calculated using the following equation [21]:

$\sigma e q, W=\sigma a \gamma \sigma \max 1-\gamma$

where $\gamma$ is a fitting constant, adjustable based on the sensitivity of the material to mean stress. The value of $\gamma=0.4$ for the Walker model was used in the analyses, as suggested by Dowling et al. [21] for materials with high sensitivity to mean stress.

\section{Kwofie Model}

Kwofie [25] proposed a mean stress correction model that considers an exponential form for the fully reversed equivalent stress amplitude (EFRSA). The EFRSA based on the Kwofie model is expressed as:

$\sigma e q, K=\sigma a e \alpha \sigma m \sigma u$

where $\sigma_{m}$ and $\sigma_{a}$ are the mean stress and stress amplitude, respectively, and $\sigma_{u}$ is the ultimate tensile stress of the material. In the Kwofie model, $\alpha$ accounts for the sensitivity of the fatigue life to mean stress and $\alpha=2.0$ was used in this study (as suggested by Kwofie for materials with high sensitivity to mean stress) to correlate fatigue lives from tests with and without mean stress/strain.

Calculated equivalent fully reversed stress amplitudes (EFRSAs) for different models are listed in Table 2 and plotted against the experimentally observed fatigue lives in Fig. 5. As can be seen in this figure for the stress-life analysis, none of the considered mean stress correction models provided satisfactory results. Among other stress-based approaches, Gerber model has been shown not to be very effective for mean stress correction of common metals [21]. Morrow's stress-based model [20] requires knowing $\sigma_{f}$ which was not available for the superelastic NiTi, and thus, was also excluded from this study. 


\section{4-2- Strain-Life Analysis}

One approach in strain-based fatigue analysis of nonzero mean strain/stress data, as Dowling [26] explains, is to relate the strain amplitude to an equivalent fully reversed fatigue life using a Coffin-Manson-type equation as:

$\varepsilon a=\sigma f^{\prime} E 2 N e q b+\varepsilon f^{\prime} 2 N e q c$

Where $\sigma f^{\prime}$ is the fatigue strength coefficient, $\varepsilon f^{\prime}$ is the fatigue ductility coefficient, $b$ is the fatigue strength exponent and $c$ is the fatigue ductility exponent, which are all determined based on the fully reversed strain-controlled fatigue data. $N_{e q}$ in this equation is the equivalent fully reversed fatigue life ( $2 N_{e q}$ is the equivalent number of reversals to failure), which is calculated based on the employed mean stress correction model and corresponds to the case of $\sigma_{m}=0$.

It should be noted that $\varepsilon f^{\prime}$ and $c$ in Eq. (7) may be related to superelasticity behavior, rather than ductility (i.e. plastic deformation) for superelastic NiTi, as its deformation can still be recoverable beyond the linear elastic region (i.e. start of plateau stress). Therefore, $\varepsilon f^{\prime}$ and $c$ may be defined as superelasticity coefficient and exponent, respectively.

To calculate the fatigue strength and superelasticity parameters, the strain amplitude of each fully reversed fatigue test is decomposed into two different portions: elastic strain amplitude, $\varepsilon_{a, e}$, and transformed strain amplitude, $\varepsilon_{a, t r}$, using the following equation [27]:

$\varepsilon a=\Delta \varepsilon 2=\varepsilon a, e+\varepsilon a, t r=\sigma a E+\varepsilon a, t r$

Thus, the transformation strain amplitude can be calculated as:

$\varepsilon a, \operatorname{tr}=\varepsilon a-\sigma a E$

Based on the least square fit to the fully reversed fatigue data generated in this study, the fatigue strength and superelasticity parameters are calculated to be $\sigma f^{\prime}=1355 \mathrm{MPa}, b=-0.085$, 
$\varepsilon f^{\prime}=2.11$ and $c=-0.679$, as presented in Fig. 6 . It is worth mentioning that the relatively large

$\varepsilon f^{\prime}$ and $c$, obtained in this study, may be resulting from the significant reduction in the fatigue life for strain levels larger than $\mathrm{A} \rightarrow \mathrm{M}$ start strain, $\varepsilon s A M$, affecting the slope, and therefore, the intercept of the transformed strain-life curve.

In the following sections, strain amplitudes of the nonzero mean strain/stress data are plotted against the equivalent fully reversed fatigue lives, calculated based on different strain-based mean stress correction models. The prediction line for all the employed models was obtained by fitting the Coffin-Manson-type equation to the fully reversed strain-controlled fatigue data. For nonzero mean strain tests, the prediction line is used to calculate the equivalent fully reversed fatigue life, $N_{e q}$, for a selected strain amplitude. The predicted fatigue life, $N_{f}$, can then be calculated using the relation between $N_{f}$ (i.e. predicted fatigue life) and $N_{e q}$ (i.e. equivalent fully reversed fatigue life) based on the selected strain-based mean stress correction model.

\section{Goodman Model}

Based on the original Goodman mean stress correction equation, the relationship between the Goodman equivalent fully reversed life, $N e q, G$, of the nonzero mean strain/stress data and the experimentally observed fatigue life, $N f$, can be written as [26]:

$N e q, G=N f 1-\sigma m \sigma u 1 / b$

where $\sigma m$ is mean stress, $\sigma u$ is the ultimate tensile stress of the material and $b$ is the fatigue strength exponent. 


\section{SWT Model}

The relationship between the Smith-Watson-Topper (SWT) equivalent fully reversed fatigue life, $N_{e q, S W T}$, for the nonzero mean strain/stress data and the experimentally observed fatigue life, $N_{f}$, can be written as [26]:

$N e q, S W T=N f 1-R \sigma 21 / 2 b$

Using Eq. (11), the SWT equivalent fully reversed fatigue lives were determined based on the experimental fatigue lives and the stress response at the stable cycle.

\section{Walker Model}

The relationship between the Walker equivalent fully reversed fatigue life, $N_{e q, W}$, for the nonzero mean strain/stress data and the experimentally expected fatigue life, $N_{f}$, can be written as [26]:

$N e q, W=N f 1-R \sigma 2(1-\gamma) / b$

where $R_{\sigma}$ is the stress ratio and $b$ is the fatigue strength exponent that holds the same value as that in Eq. (7). $\gamma$ is a fitting constant, which is adjustable based on the sensitivity of the material to mean stress. Similar to the stress-life analysis, a value of $\gamma=0.4$ was used in Eq. (12).

\section{Kwofie Model}

The relationship between the Kwofie equivalent fully reversed fatigue life, $\mathrm{Neq}, \mathrm{K}$, for the nonzero mean strain/stress data and the experimentally expected fatigue life, $N f$, can be written as [25]:

$N e q, K=N f e-\alpha \sigma m \sigma u / b$

where $\alpha$ accounts for the sensitivity of the fatigue life to mean stress. Similar to the stress-life analysis, a value of $\alpha=2.0$ was considered in Eq. (13). 
Strain amplitudes are plotted against equivalent fully reversed fatigue lives based on Goodman, SWT, Walker, and Kwofie models in Fig. 7(a) to (d), respectively. In these figures, the Coffin-Manson fit to the fully reversed data is used as the prediction line to calculate the equivalent fully reversed fatigue life, $N_{\text {eq }}$. The predicted fatigue life, $N_{f}$, can then be calculated based on $N_{e q}$ using equations (10)-(13) for each model. As can be seen in Fig. 7(a) to (d), none of the employed mean stress correction models provided close correlation between zero and nonzero mean strain/stress test data. In the LCF regime (i.e. large strain amplitudes), however, the results based on strain-life analysis are slightly improved as compared to the stress-life analysis.

\section{Morrow Model}

In Morrow's strain-based mean stress correction model, the mean stress effects on fatigue life is accounted for by replacing the $\sigma f^{\prime}$ in the Coffin-Manson equation (i.e. Eq. (7)) with $\sigma f^{\prime}-\sigma m$.

Therefore, the Morrow's model for mean stress correction can be written as [20]:

$\varepsilon a=\sigma f^{\prime}-\sigma m E 2 N f b+\varepsilon f^{\prime} 2 N f c$

where the coefficients and exponents are similar to those in Eq. (7) and $\sigma_{m}$ is mean stress. For the Morrow model, however, it is not possible to generate a strain-life plot, and therefore, the results will be discussed in a life-life plot later.

\section{SWT Parameter}

The SWT damage parameter, defined as the product of the strain amplitude and maximum stress, i.e. $\varepsilon_{a} \sigma_{\max }$, can also be utilized directly to consider the effects of mean stress on the fatigue behavior. The relation between the damage parameter and the fatigue life of a specimen with $\varepsilon_{a}$ and $\sigma_{\max }$ (obtained from the stable cycle response) can be expressed as [19]: 
$\varepsilon a \sigma \max =\left(\sigma f^{\prime}\right) 2 \quad E 2 N f 2 b+\sigma f^{\prime} \varepsilon f^{\prime} 2 N f b+c$

The corresponding SWT damage parameter for tests at different strain ratios are plotted against the experimental fatigue lives in Fig. 7(e). As seen, the SWT model underestimates detrimental effects of the tensile mean stress on the fatigue behavior. Based on Fig. 7, none of the employed mean stress correction models in strain-life analysis provided satisfactory results for superelastic NiTi.

\section{4-3- A Modified Energy-Based Approach}

Energy methods have been developed for fatigue analysis of various materials under uniaxial [28,29] and multiaxial loading [30-32]. Moumni et al. [11] employed an energy damage parameter, equal to the area inside stress-strain response, and correlated fatigue lives of superelastic NiTi specimens with different stress ratios $\left(R_{\sigma}\right)$ fairly well. As the energy-based damage parameter utilized by Moumni et al. is equal to the area of the hysteresis loop of loading and unloading curve, it does not consider the effects of tensile mean stress separately. Therefore, it assigns the same damage parameter for two tests with different maximum stresses as long as the hysteretic areas are the same. Moreover, their proposed model does not assign any fatigue damage for the cyclic tests in the linear elastic regime, while experimental observations [6] have revealed fatigue failure in this range.

In this study, the energy method proposed by Ellyin and co-authors [33-35] has been adopted with some modifications to correlate fatigue data of superelastic NiTi with and without mean strains/stresses. The energy approach employed in this study can be explained by considering different energies associated with cyclic response of the superelastic NiTi, presented in Fig. 8. In this figure, $W_{d}$ is the dissipated energy density of one cycle, equivalent to the area encompassed by the loading and unloading curves. Of course, for fully reversed tests $W_{d}$ should be calculated 
for both tension and compression portions of the stress-strain response. Fig. 8(a) schematically presents the dissipated strain energy density, $W_{d}$, and the superelastic energy density, $W_{s e}+$ (equivalent to the elastic energy density for common metals) that takes into account the effect of tensile mean stress on the fatigue damage. However, the deformation on the stress plateau (where $\varepsilon s A M<\varepsilon_{\max }<\varepsilon f A M$ ) is mostly driven by the phase transformation in superelastic NiTi, and thus, should be excluded from the damage parameter. Therefore, only the dissipated energy density, $W_{d}$, and the tensile elastic energy density, $W e+$, should be included in the damage parameter, as presented in Fig. 8(b). It is worth mentioning that $W e+$ represents the portion of tensile deformation, which is driven by external loading (i.e. tensile stress). The tensile elastic energy density, $W e+$, in Fig. 8(b) can be calculated using the following equation:

\section{We $+=\sigma \max 22 E A$}

where $\sigma_{\max }$ is the maximum stress and $E_{A}$ is the austenite modulus of the material. Since $\sigma_{\max }=$ $\sigma_{m}+\sigma_{a}, W e+$ accounts for the effects of tensile mean stress (i.e. the static portion of the loading) on the fatigue damage [28,33]. In both Ellyin and the proposed energy-based damage parameters, the compressive elastic energy density is not considered in the models, as it is known that the compressive mean stress does not affect the fatigue behavior.

Therefore, the total energy density, $W t$, considered as the damage parameter in this study, is the sum of dissipated energy density, $W d$, and tensile elastic energy density, $W e+$ :

$W t=W d+W e+$ 
The proposed damage parameter as the total strain energy density for the superelastic NiTi is calculated for each test, based on the stable cycle of the stress-strain response, and listed in Table 2 and presented in Fig. 9(a) against the experimental fatigue life. As can be seen from this figure, the proposed energy approach provides reasonable correlations among the fatigue data for various strain ratios considered in this study. The prediction line in Fig. 9(a), is obtained by a power-law equation fit to the pulsating fatigue test data (i.e. $R_{f}=0$ ), since a wider range of strain amplitudes was available for this set of data.

Another attempt was made in this study to evaluate the applicability of the energy approach using the stress-strain response of the first cycle instead of the stable response.

The calculated energy damage parameter based on the first cycle for each test is listed in Table 2 and plotted against the experimental fatigue life in Fig. 9(b). The correlation of fatigue data from various strain ratios based on the first cycle energy parameter is almost as good as the one based on the stable response, which can be noticed by comparing the results in Fig. 9(a) and (b).

\section{5- Discussions on Prediction Models}

Predicted fatigue lives, using different approaches considered in this study, are compared to experimental fatigue lives for all strain ratios in Fig. 10. For all the plots in this figure, the horizontal and vertical axes are experimentally observed and predicted reversals to failure (i.e. $2 N_{f}$ ), respectively. In all the life-life plots, a vertical arrow means a predicted infinite life, a horizontal arrow depicts an experimentally observed infinite life (i.e. run-out), and a 45-degree arrow indicates that both predicted and experimental lives are infinite.

Predicted fatigue lives using various mean stress correction models in stress-life approach are presented against the experimentally observed fatigue lives in Figs. 10(a) to (d). One important 
conclusion based on the these figures is the fact that predictions based on stress-life methods are non-conservative and result in significant underestimation of fatigue damage in presence of tensile mean stress/strain. This may indicate higher sensitivity of the superelastic NiTi to tensile mean stress as compared to some other typical metallic materials.

As can be seen in Fig. 5, in stress-life analysis, all the employed mean stress correction models assign a very small EFRSA to the nonzero mean strain tests, which is less than the EFRSA of the run-out fully reversed test. As a result, infinite fatigue lives are predicted for nonzero mean strain tests, as can be seen in Figs. 10(a) to (d). Very small EFRSA, calculated by all the mean stress correction models in the stress-life approach, may be explained by the superelasticity, i.e. the stress plateaus in stress-strain response, of the superelastic NiTi. For fatigue tests with a maximum strain between the $\mathrm{A} \rightarrow \mathrm{M}$ start and finish strains, the maximum stress response does not change, and is almost constant, resulting in the same stress amplitude and mean stress for a wide range of strains. Consequently, the equivalent stress will be the same for tests at the strain levels corresponding to the stress plateau region, implying the same fatigue damage, while experiments show differences in fatigue lives for tests in this strain range.

This is even more evident for $R_{\varepsilon}=0.5$ condition, where the strain range falls on the stress plateau region. In this case, stress range is almost constant and cannot exceed the difference of loading and unloading stress plateaus, regardless of the strain range. Now, let us consider two different tests in Fig. 11 with the same strain amplitude, but different strain ratios of $R_{\varepsilon}=0$ and 0.5. Although both tests have the same strain amplitude, the stress range is significantly larger for the test with $R_{\varepsilon}=0$ (indicated by the solid line in Fig. 11). Consequently, using classical mean stress models in stress-life analysis, a larger EFRSA is calculated for $R_{\varepsilon}=0$ test; therefore, a shorter fatigue life is predicted for this test as compared to the life predicted for the test with $R_{\varepsilon}$ 
$=0.5$ (indicated by the dashed line in Fig. 11). This is, however, in contrast with experimental observations that the $R_{\varepsilon}=0.5$ test had significantly shorter fatigue life than the $R_{\varepsilon}=0$ test.

Predicted fatigue lives, employing different mean stress correction models in strain-life approach, are compared to the experimentally observed fatigue lives in Figs. 10(e) to (i). As can be seen in these figures while fatigue life predictions are slightly better than the ones obtained in stress-life approach, especially in LCF regime (i.e. larger strain amplitudes), most predicted finite fatigue lives even do not fall within prediction bands of hundred (i.e. $\times 100$ lines). In strainlife analysis based on the equivalent fully reversed fatigue life, none of the mean stress correction models predict fatigue failure for small strain amplitudes (i.e. $\varepsilon_{a}<1.0 \%$ ), regardless of the amount of mean stress. For these tests, the strain amplitudes fall below the strain endurance limit (strain at which the fatigue life was very long under fully reversed loading); thus, infinite fatigue lives are predicted (see Fig. 7), while finite fatigue lives were experimentally observed.

Moreover, none of the discussed mean stress/strain correction models, consider the special shape of the stress-strain hysteresis response of superelastic NiTi. As a result of the loading and unloading stress plateaus in the superelastic regime, not a major change in stress occurs in response to a significant change in strain. In other words, for the tests where the strain range falls on the stress plateau, the strain variations are not directly reflected in the stress response of the material. Thus, mean stress correction models based on only mean or maximum stress terms cannot fully account for the effect of mean strain and phase change on the fatigue resistance of superelastic NiTi. For example, using the SWT or Walker models the same damage will be calculated for both test conditions illustrated in Fig. 11, having the same strain amplitudes and approximately similar maximum stresses. As a result, similar fatigue lives will be predicted for both tests, while experiments have shown significantly shorter fatigue lives for $R_{\varepsilon}=0.5$ tests. 
The effects of the unique stress-strain shape of the superelastic NiTi cannot then be completely captured by the "classical" fatigue theories for mean stress/strain effects, as also reported elsewhere [36].

Among the strain-life mean stress correction approaches employed, the Morrow model provides somewhat more reasonable fatigue life predictions, as seen in Fig. 10(i). All the predicted fatigue lives, fall within prediction bands of twenty-five from the experimental fatigue lives using Morrow model. For this model, a predicted fatigue life was considered infinite when it was longer than the set run-out life. For all the previously discussed models, however, fatigue life for a strain amplitude smaller than the fatigue strain endurance was predicted as infinite. This may explain the better fatigue life predictions obtained by Morrow as compared to the other models.

Comparison of the predicted and experimental fatigue lives using SWT parameter is presented in Fig. 10(j). As can be seen in this figure, the SWT parameter underestimates the fatigue damage in presence of tensile mean strain in both LCF and HCF regimes; thus, predicts nonconservative fatigue lives. Similar to strain-life analysis, an infinite fatigue life is predicted when the SWT damage parameter is smaller than the one for the run-out test (see Fig. 7(e)). Predicted finite fatigue lives using SWT parameter are somewhat more reasonable, as the data fall within prediction bands of ten. It should be mentioned that the SWT parameter can be considered as an energy model, which is based on the elastic energy density on a critical plane within the material $[37,38]$.

Although different fatigue lives were observed for specimens with the same strain amplitude, but different strain ratios of $R_{\varepsilon}=0$ and 0.5 (as seen in Fig. 3), almost identical SWT damage values are calculated for these tests. This is mainly as a result of stress plateau in superelastic 
$\mathrm{NiTi}$, keeping the $\sigma_{\max }$ constant at strains larger than $\varepsilon s A M=1.0 \%$. In other words, as the maximum strains for these specimens fall between the $\mathrm{A} \rightarrow \mathrm{M}$ start and finish strains, the maximum stress is almost constant [16]. Consequently, similar SWT damage values are calculated for these specimens resulting in similar predicted fatigue lives. Nevertheless, this is against our experimental observations that the presence of tensile mean strains can significantly reduce the fatigue resistance of superelastic NiTi. Thus, one may conclude that the SWT parameter may not be the most appropriate model to account for the effects of tensile mean strain/stress on the fatigue behavior of superelastic NiTi alloys.

Predicted fatigue lives using the proposed energy-based damage parameter are plotted against the experimental fatigue lives in Figs. $10(\mathrm{k})$ and (1), based on the stable and first cycles of the stress-strain response, respectively, for all superelastic NiTi data in this study. According to these figures, the predicted fatigue lives fall within prediction bands of two from experimental fatigue lives using either stable cycle or first cycle damage parameters, illustrating a robust prediction capability using the proposed fatigue model. As can be seen from Fig. 9, the proposed model assigns the smallest value for the specimen that failed in the grip, indicating a longer fatigue life, which is consistent with experimental observations.

It should be noted that although the predictions using the first cycle damage parameter are close to those obtained based on the stable cycle, the first cycle predictions exhibit a lower $\mathrm{R}^{2}$ value. This may be due to the fact that the stable cycle damage parameter, calculated based on the stable cycle of the stress strain response, considers the cyclic characteristics of the material response such as the hysteresis loop evolution, cyclic hardening/softening, etc. On the other hand, although the cyclic hardening/softening as well as mean stress relaxation effects on fatigue behavior are ignored by using the first cycle strain energy densities, this will eliminate the need 
for conducting extensive fatigue/cyclic experiments, which are typically time and cost consuming. In order to calculate the damage parameter based on the first cycle, one strainingunstraining cycle up to the end of the stress plateau for each $R_{\varepsilon}$ (and at the same strain rate as the cyclic tests) will be adequate. This facilitates calculating strain energy densities as long as the maximum applied strain is within the superelastic region.

One advantage of the proposed energy-based approach over the stress-life and strain-life mean stress correction models is the fact that the proposed energy approach accounts for the constitutive response of the material, and thus, the shape of the stress-strain curve (i.e. hysteresis loop). In other words, the proposed energy model is able to consider the unique stress-strain response of superelastic NiTi by incorporating the stress-strain path during loading and unloading into the model. On the other hand, this indicates a need for developing cyclic constitutive models for superelastic NiTi $[39,40]$ that take into account various aspects of cyclic loading, such as strain rate, mean stress relaxation, and strain hardening/softening, to be able to calculate strain energy densities for the stable stress-strain response of the material.

In order to illustrate the correlation between fatigue lives of superelastic NiTi specimens and the energy parameter, the mid-life (i.e. stable) hysteresis loop of three different specimens with different strain ratios $\left(R_{\varepsilon}=-1,0\right.$, and 0.5$)$ tested at the same strain amplitudes $\left(\varepsilon_{a}=1.0 \%\right)$ are compared in Fig. 12. As can be seen from this figure, the specimen tested in fully reversed condition, with a fatigue life greater than 67,000 cycles, exhibits very small amounts of dissipated and tensile elastic energy densities when compared to other tests. Thus, the energybased damage parameter for this test, calculated by Eq. (17), is much smaller than the ones with $R_{\varepsilon}=0$, and 0.5 ; thus, correctly predicting a much longer fatigue life for the fully reversed test. Nevertheless, the specimen tested at $R_{\varepsilon}=0.5$ has a large hysteresis loop (i.e. dissipated energy 
density) and tensile elastic energy density, leading to a larger total strain energy density. Therefore, the fatigue life of this specimen $\left(N_{f}=1,533\right.$ cycles $)$ is the shortest of the three tests. The pulsating test has a total strain energy density, as the employed damage parameter, between those for the fully reversed $\left(R_{\varepsilon}=-1\right)$ and tension-tension $\left(R_{\varepsilon}=0.5\right)$ tests, and therefore, the specimen's fatigue life ( $N_{f}=2,333$ cycles) falls between the ones from the other two tests.

\section{6- Conclusions}

Strain-controlled fatigue experiments with and without mean strains $\left(R_{\varepsilon}=-1,0\right.$, and 0.5$)$ were conducted to evaluate the applicability of various mean stress/strain correction models for fatigue life analysis of superelastic NiTi. Based on the experimental observations and analysis results, the following conclusions can be made:

1. As a result of loading and unloading stress plateaus in the superelastic NiTi, the variations of the strain range is not always reflected in the stress response. Therefore, classical mean stress correction models, such as Goodman or SWT parameters, are not appropriate for the fatigue analysis of this material.

2. An energy-based approach based on the sum of the dissipated and tensile elastic strain energy densities, accounting for the unique shape of the superelastic NiTi hysteresis loop, could fairly correlate the experimental fatigue data under different mean strain/stress conditions.

3. There is a critical need for developing cyclic constitutive relations for superelastic NiTi as a requirement for energy-based fatigue analysis. The constitutive equation should be able to predict various aspects of cyclic behavior of the material such as cyclic hardening/softening, strain rate effects, mean stress relaxation, etc. 
4. Although the energy-based damage parameter based on the first cycle response is easier to obtain and provides reasonable predictions, the stable cycle response accounts for the various aspects of cyclic behavior such as cyclic hardening, hysteresis loop evolution and mean stress relaxation.

\section{Acknowledgements}

This material is based upon work partially supported by the National Science Foundation under grant No. 1549973. Authors would also like to thank Benjamin Rutherford for his assistance with fatigue tests. This manuscript was prepared while Nima Shamsaei was an

Assistant

Professor

at

Mississippi

State

University. 


\section{References}

[1] M.S. Saiidi, H. Wang, Exploratory study of seismic response of concrete columns with shape memory alloys reinforcement, Struct. J. 103 (2006). doi:10.14359/15322.

[2] F. Butera, Shape memory actuators for automotive applications, Adv. Mater. Process. 166 (2008) 37.

[3] F.T. Calkins, J.H. Mabe, Shape memory alloy based morphing aerostructures, J. Mech. Des. 132 (2010) 111012.

[4] M.J. Mahtabi, N. Shamsaei, M.R. Mitchell, Fatigue of Nitinol: The state-of-the-art and ongoing challenges, J. Mech. Behav. Biomed. Mater. 50 (2015) 228-254. doi:10.1016/j.jmbbm.2015.06.010.

[5] S.W. Robertson, A.R. Pelton, R.O. Ritchie, Mechanical fatigue and fracture of Nitinol, Int. Mater. Rev. 57 (2012) 1-37.

[6] A.R. Pelton, J. Fino-Decker, L. Vien, C. Bonsignore, P. Saffari, M. Launey, M.R. Mitchell, Rotary-bending fatigue characteristics of medical-grade Nitinol wire, J. Mech. Behav. Biomed. Mater. 27 (2013) 19-32.

[7] ASTM E2948-14, Test method for conducting rotating bending fatigue tests of solid round fine wire, ASTM International, West Conshohocken, PA, 2014. http://www.astm.org/doiLink.cgi?E2948 (accessed April 20, 2015).

[8] D. Tolomeo, S. Davidson, M. Santinoranont, Cyclic properties of superelastic Nitinol: design implications, in: SMST-2000 Proc. Int. Conf. Shape Mem. Superelastic Technol. SM Russell AR Pelton Eds Pac. Grove Calif. USA, 2000: pp. 471-6.

[9] A.R. Pelton, X.-Y. Gong, T. Duerig, Fatigue testing of diamond-shaped specimens, in: Med. Device Mater.-Proc. Mater. Process. Med. Devices Conf., 2003: pp. 199-204.

[10] N.B. Morgan, J. Painter, A. Moffat, Mean strain effects and microstructural observations during in vitro fatigue testing of NiTi, in: SMST-2003 Proc. Int. Conf. Shape Mem. Superelastic Technol., SMST Society, Pacific Grove, CA, 2004: pp. 303-310.

[11] Z. Moumni, A.V. Herpen, P. Riberty, Fatigue analysis of shape memory alloys: energy approach, Smart Mater. Struct. 14 (2005) S287. doi:10.1088/0964-1726/14/5/017.

[12] M.J. Mahtabi, N. Shamsaei, Multiaxial fatigue modeling for Nitinol shape memory alloys under in-phase loading, J. Mech. Behav. Biomed. Mater. 55 (2015) 236-249. doi:10.1016/j.jmbbm.2015.10.022.

[13] ASTM E606 / E606M-12, Test method for strain-controlled fatigue testing, ASTM International, West Conshohocken, PA, 2012. www.astm.org (accessed July 10, 2014). 
[14] A.R. Pelton, J. Dicello, S. Miyazaki, Optimisation of processing and properties of medical grade Nitinol wire, Minim. Invasive Ther. Allied Technol. 9 (2000) 107-118.

[15] A.R. Pelton, V. Schroeder, M.R. Mitchell, X.-Y. Gong, M. Barney, S.W. Robertson, Fatigue and durability of Nitinol stents, J. Mech. Behav. Biomed. Mater. 1 (2008) 153-164.

[16] M.J. Mahtabi, N. Shamsaei, B. Rutherford, Mean strain effects on the fatigue behavior of superelastic Nitinol alloys: an experimental investigation, Procedia Eng. 133 (2015) 646654. doi:10.1016/j.proeng.2015.12.645.

[17] S. Miyazaki, T. Imai, Y. Igo, K. Otsuka, Effect of cyclic deformation on the pseudoelasticity characteristics of Ti-Ni alloys, Metall. Trans. A. 17 (1986) 115-120.

[18] F. Auricchio, E. Sacco, A one-dimensional model for superelastic shape-memory alloys with different elastic properties between austenite and martensite, Int. J. Non-Linear Mech. 32 (1997) 1101-1114. doi:10.1016/S0020-7462(96)00130-8.

[19] S. Miyazaki, K. Mizukoshi, T. Ueki, T. Sakuma, Y. Liu, Fatigue life of Ti-50 at.\% Ni and Ti-40Ni-10Cu (at.\%) shape memory alloy wires, Mater. Sci. Eng. A. 273-275 (1999) 658663.

[20] R.I. Stephens, A. Fatemi, R.R. Stephens, H.O. Fuchs, Metal fatigue in engineering, Second, Wiley, 2000.

[21] N.E. Dowling, C.A. Calhoun, A. Arcari, Mean stress effects in stress-life fatigue and the Walker equation, Fatigue Fract. Eng. Mater. Struct. 32 (2009) 163-179. doi:10.1111/j.1460-2695.2008.01322.x.

[22] G. Eggeler, E. Hornbogen, A. Yawny, A. Heckmann, M. Wagner, Structural and functional fatigue of NiTi shape memory alloys, Mater. Sci. Eng. A. 378 (2004) 24-33.

[23] K.N. Smith, P. Watson, T.H. Topper, A stress-strain parameter for the fatigue of metals, J. Mater. 5 (1970) 767-778.

[24] K. Walker, The effect of stress ratio during crack propagation and fatigue for 2024-T3 and 7075-T6 aluminum, Am. Soc. Test. Mater. ASTM STP 462 (1970) 1-14.

[25] S. Kwofie, An exponential stress function for predicting fatigue strength and life due to mean stresses, Int. J. Fatigue. 23 (2001) 829-836. doi:10.1016/S0142-1123(01)00044-5.

[26] N.E. Dowling, Mean stress effects in strain-life fatigue, Fatigue Fract. Eng. Mater. Struct. 32 (2009) 1004-1019. doi:10.1111/j.1460-2695.2009.01404.x.

[27] A. Runciman, D. Xu, A.R. Pelton, R.O. Ritchie, An equivalent strain/Coffin-Manson approach to multiaxial fatigue and life prediction in superelastic Nitinol medical devices, Biomaterials. 32 (2011) 4987-4993. doi:10.1016/j.biomaterials.2011.03.057.

[28] D. Kujawski, F. Ellyin, A unified approach to mean stress effect on fatigue threshold conditions, Int. J. Fatigue. 17 (1995) 101-106. doi:10.1016/0142-1123(95)95888-N. 
[29] R. Shrestha, J. Simsiriwong, N. Shamsaei, R.D. Moser, Cyclic deformation and fatigue behavior of polyether ether ketone (PEEK), Int. J. Fatigue. 82, Part 3 (2016) 411-427. doi:10.1016/j.ijfatigue.2015.08.022.

[30] T. Łagoda, E. Macha, M. Sakane, Estimation of high temperature fatigue lifetime of SUS304 steel with an energy parameter in the critical plane, J. Theor. Appl. Mech. 41 (2003) 55-73.

[31] A. Varvani-Farahani, A new energy-critical plane parameter for fatigue life assessment of various metallic materials subjected to in-phase and out-of-phase multiaxial fatigue loading conditions, Int. J. Fatigue. 22 (2000) 295-305. doi:10.1016/S0142-1123(00)00002-5.

[32] B.-M. Lei, V.-X. Tran, S. Taheri, J.-C. le Roux, F. Curtit, M. He, L. Wan, Y. Zhou, Toward consistent fatigue crack initiation criteria for 304L austenitic stainless steel under multiaxial loads, Int. J. Fatigue. 75 (2015) 57-68. doi:10.1016/j.jjfatigue.2015.02.001.

[33] F. Ellyin, D. Kujawski, A multiaxial fatigue criterion including mean-stress effect, ASTM Spec. Tech. Publ. 1191 (1993) 55-55.

[34] F. Ellyin, Z. Xia, A general fatigue theory and its application to out-of-phase cyclic loading, J. Eng. Mater. Technol. 115 (1993) 411-416. doi:10.1115/1.2904239.

[35] K. Golos, F. Ellyin, A total strain energy density theory for cumulative fatigue damage, J. Press. Vessel Technol. 110 (1988) 36-41. doi:10.1115/1.3265565.

[36] R.M. Tabanli, N.K. Simha, B.T. Berg, Mean stress effects on fatigue of NiTi, Mater. Sci. Eng. A. 273-275 (1999) 644-648.

[37] A. Karolczuk, E. Macha, A Review of Critical Plane Orientations in Multiaxial Fatigue Failure Criteria of Metallic Materials, Int. J. Fract. 134 (2005) 267-304. doi:10.1007/s10704-005-1088-2.

[38] T. Lagoda, E. Macha, W. Bdkowski, A critical plane approach based on energy concepts: application to biaxial random tension-compression high-cycle fatigue regime, Int. J. Fatigue. 21 (1999) 431-443. doi:10.1016/S0142-1123(99)00003-1.

[39] Z. Bo, D.C. Lagoudas, Thermomechanical modeling of polycrystalline SMAs under cyclic loading, Part I: theoretical derivations, Int. J. Eng. Sci. 37 (1999) 1089-1140. doi:10.1016/S0020-7225(98)00113-X.

[40] C. Yu, G. Kang, Q. Kan, D. Song, A micromechanical constitutive model based on crystal plasticity for thermo-mechanical cyclic deformation of NiTi shape memory alloys, Int. J. Plast. 44 (2013) 161-191. doi:10.1016/j.ijplas.2013.01.001. 


\section{Figures}

Fig. 1- Solid circular fatigue specimen used in strain-controlled tests: (a) a picture of the actual specimen, and (b) drawing of the specimen (all dimensions are in $\mathrm{mm}$ )

Fig. 2- Tensile stress-strain response of NiTi from two different monotonic tests [16]

Fig. 3- Strain-life fatigue data for different strain ratios $\left(R_{\varepsilon}\right)$ [16]. Arrow indicates failure in the grip.

Fig. 4- Stress-life data for fully reversed strain-controlled tests used to calculate the prediction line and stress-life fatigue parameters; $\sigma_{f}^{\prime}$ and $b$.

Fig. 5- Equivalent fully reversed stress amplitude (EFRSA) versus experimental fatigue lives for different stress-based mean stress correction models: (a) Goodman, (b) SWT, (c) Walker, and (d) Kwofie.

Fig. 6- Fatigue coefficients and exponents calculated based on the strain decomposition of fully reversed fatigue data.

Fig. 7- Strain amplitude versus equivalent fully reversed fatigue lives for different strain-based mean stress correction models: (a) Goodman, (b) SWT, (c) Walker, (d) Kwofie, and (e) SWT parameter.

Fig. 8- Different energies associated with cyclic response of superelastic NiTi: (a) dissipated and tensile superelastic energy density, and (b) dissipated and elastic energy density.

Fig. 9- Correlation of the proposed energy-based damage parameters with experimental data: (a) Stable cycle and (b) first cycle damage parameters.

Fig. 10- Comparison of the predicted and experimental fatigue lives using (a) to (d) stress-based models, (e) to (i) strain-based models, (j) SWT parameter, (k) and (l) proposed energybased parameter. In all the figures, the horizontal axis is the experimental number of reversals to failure and the vertical axis is the predicted number of reversals to failure. Dotted lines indicate different prediction bands.

Fig. 11- Schematic representation of two tests with the same strain amplitude and different strain ratios of $R_{\varepsilon}=0$ and 0.5 .

Fig. 12- Stable cycle (mid-life) hysteresis curves of three different tests with the same strain amplitude and different strain ratios 
(a)

(b)
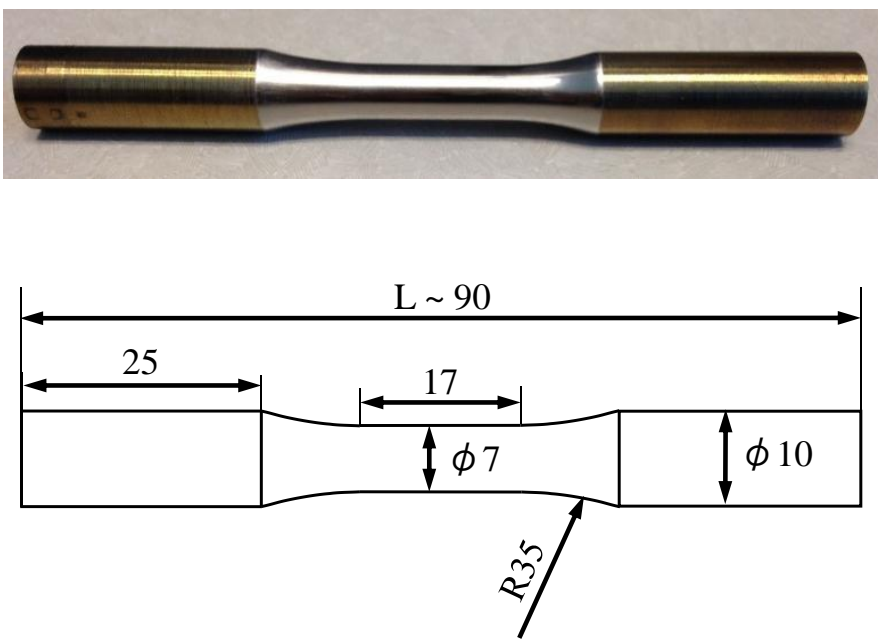

Fig. 1- Solid circular fatigue specimen used in strain-controlled tests: (a) a picture of the actual specimen, and (b) drawing of the specimen (all dimensions are in $\mathrm{mm}$ ) 


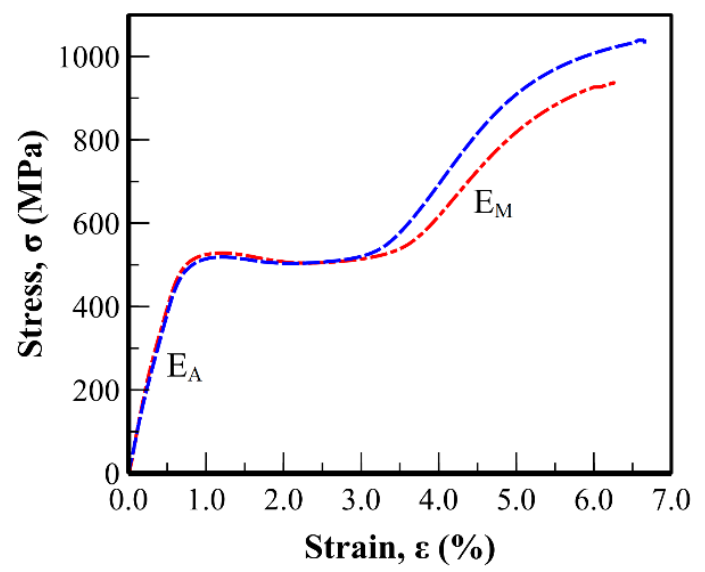

Fig. 2- Tensile stress-strain response of NiTi from two different monotonic tests [16] 


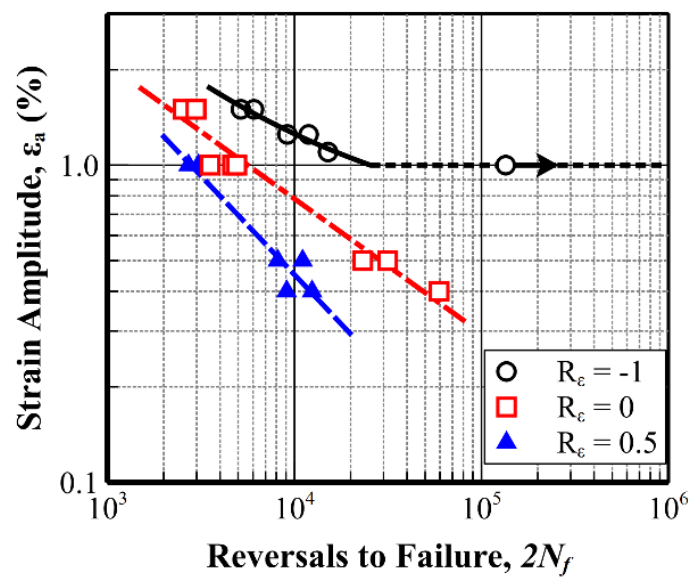

Fig. 3- Strain-life fatigue data for different strain ratios $\left(R_{\varepsilon}\right)$ [16]. Arrow indicates failure in the grip. 




Fig. 4- Stress-life data for fully reversed strain-controlled tests used to calculate the prediction line and stress-life fatigue parameters; $\sigma_{f}^{\prime}$ and $b$. 
(a) Goodman model

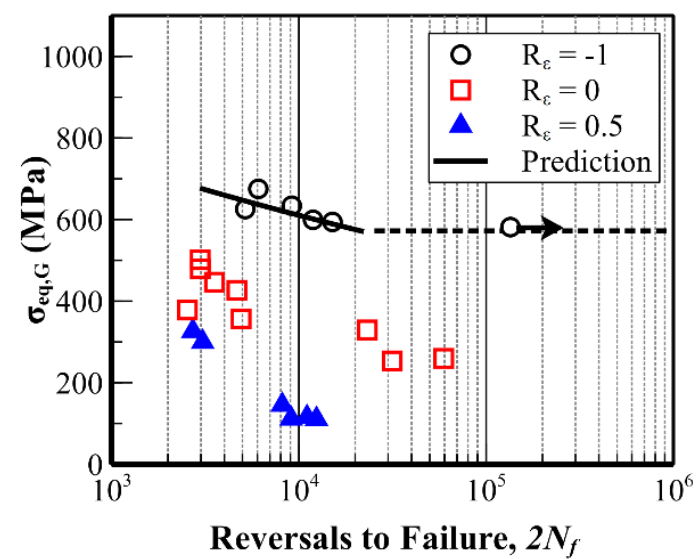

(c) Walker model

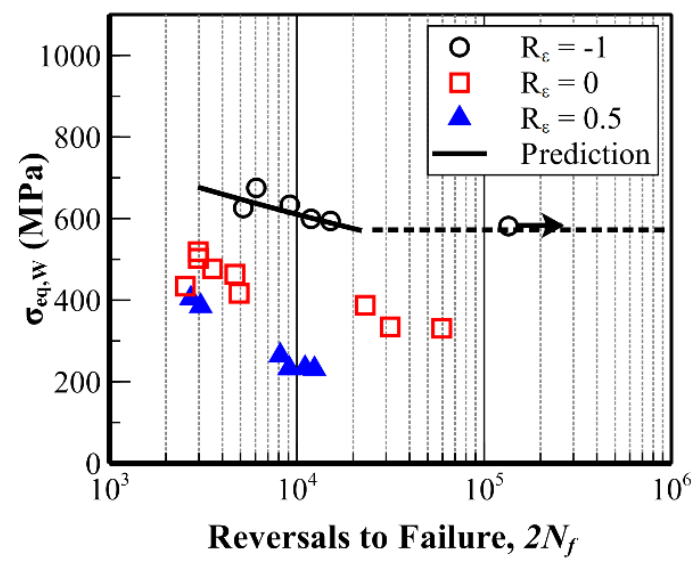

(b) SWT model

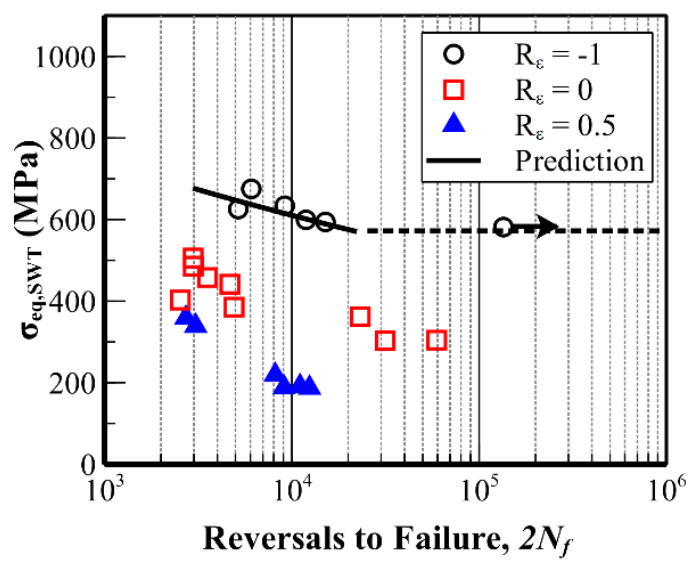

(d) Kwofie model

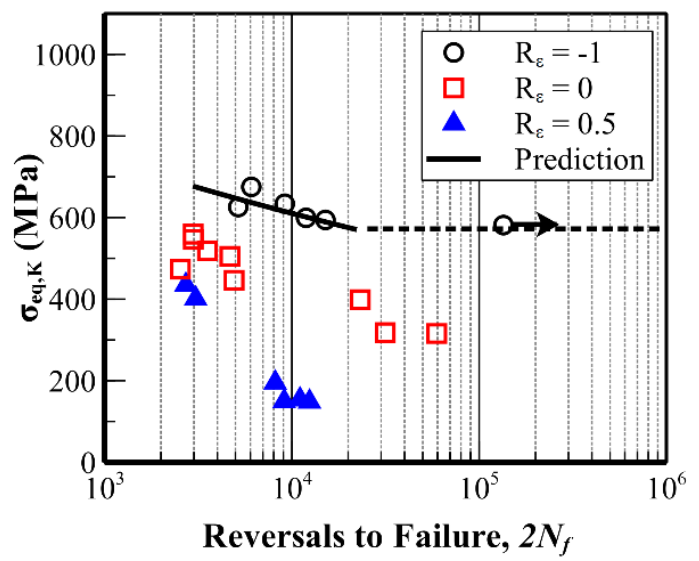

Fig. 5- Equivalent fully reversed stress amplitude (EFRSA) versus experimental fatigue lives for different stress-based mean stress correction models: (a) Goodman, (b) SWT, (c) Walker, and (d) Kwofie. 


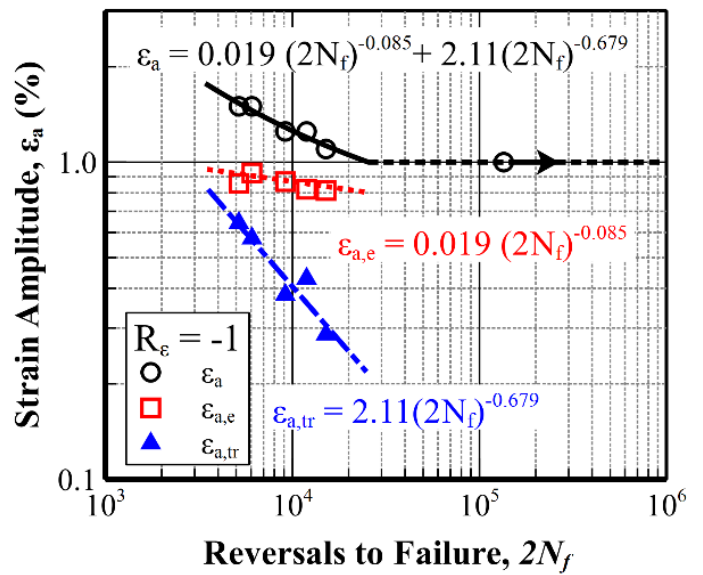

Fig. 6- Fatigue coefficients and exponents calculated based on the strain decomposition of fully reversed fatigue data. 
(a) Goodman model

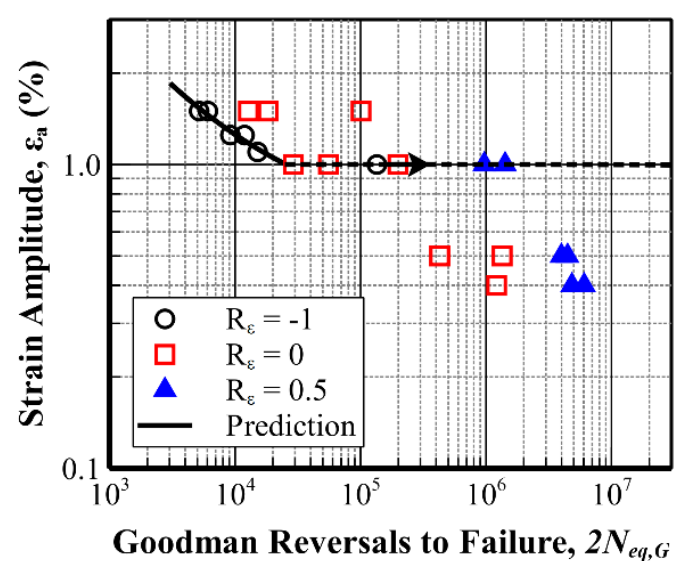

(c) Walker model

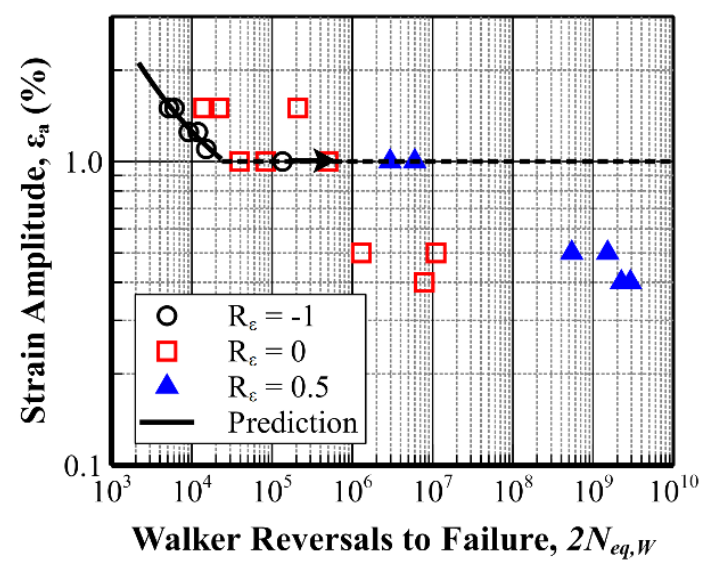

(b) SWT model

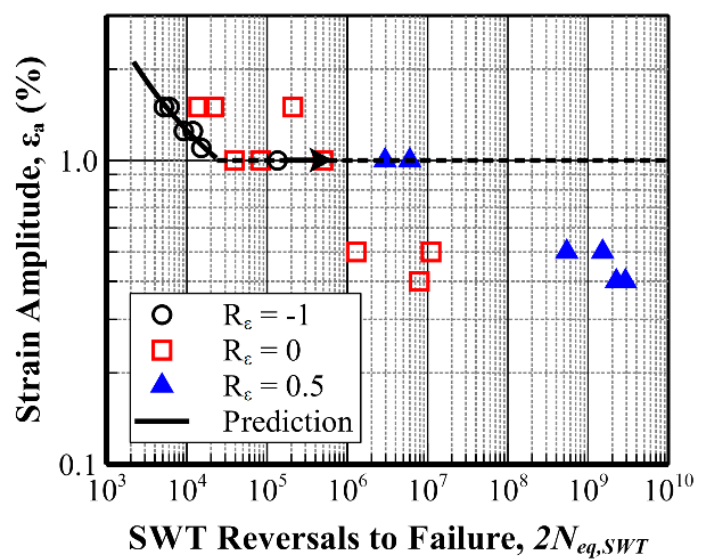

(d) Kwofie model

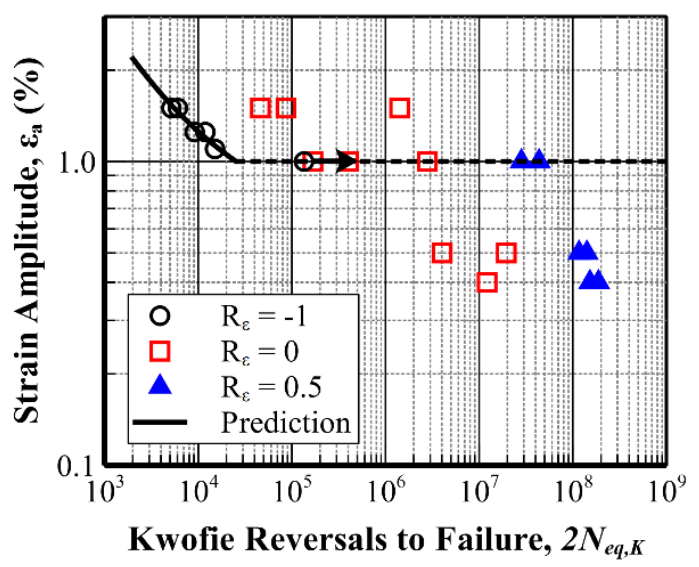

(e) SWT parameter

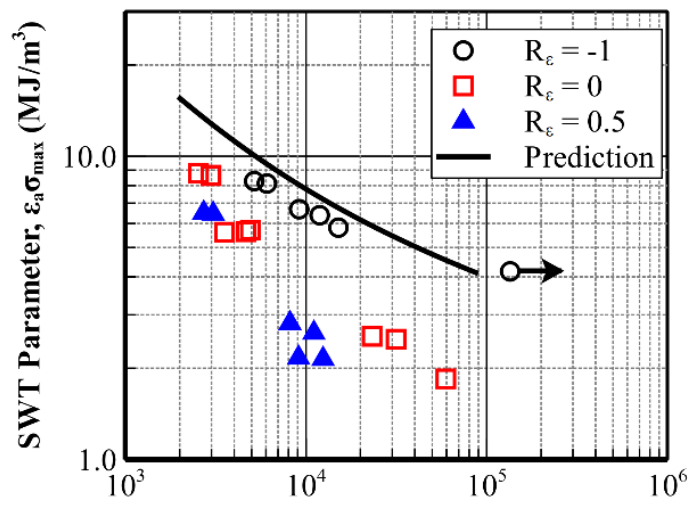

Reversals to Failure, $2 N_{f}$

Fig. 7- Strain amplitude versus equivalent fully reversed fatigue lives for different strain-based mean stress correction models: (a) Goodman, (b) SWT, (c) Walker, (d) Kwofie, and (e) SWT parameter. 


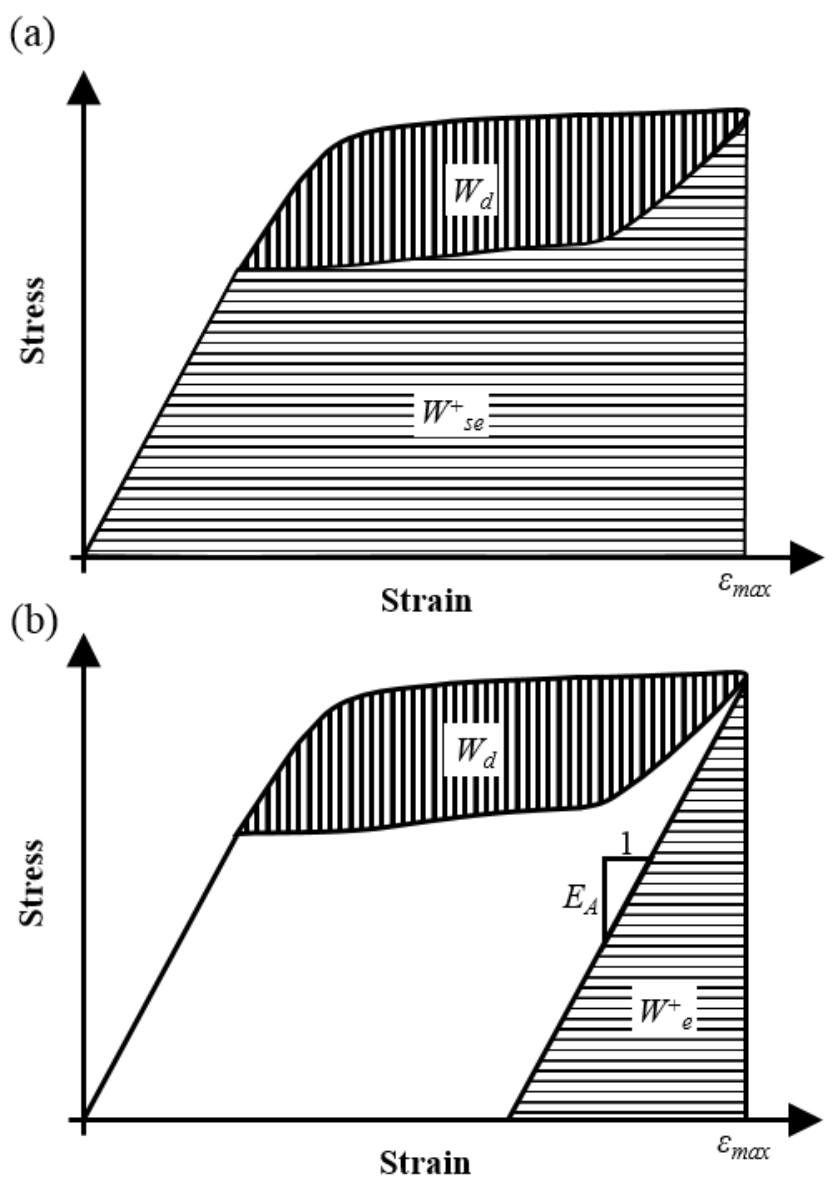

Fig. 8- Different energies associated with cyclic response of superelastic NiTi: (a) dissipated and tensile superelastic energy density, and (b) dissipated and elastic energy density. 
(a) Stable cycle energy parameter



(b) First cycle energy parameter

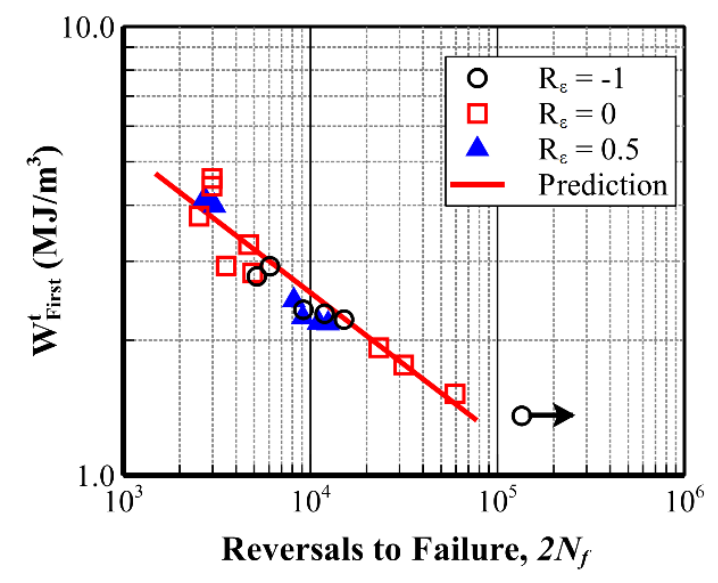

Fig. 9- Correlation of the proposed energy-based damage parameters with experimental data: (a) Stable cycle and (b) first cycle damage parameters. 
(a)

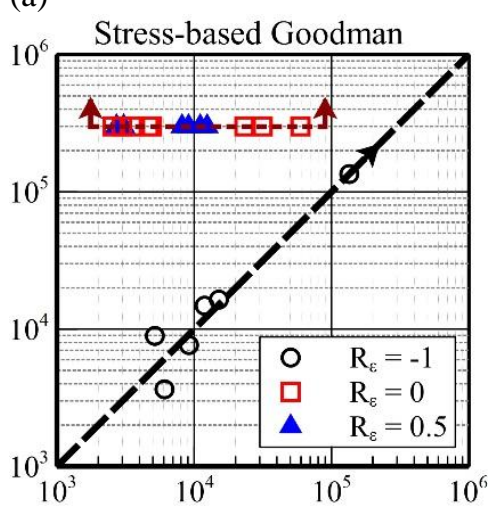

(d)

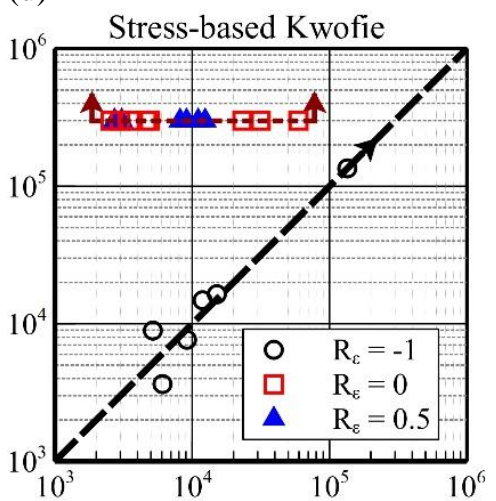

(g)

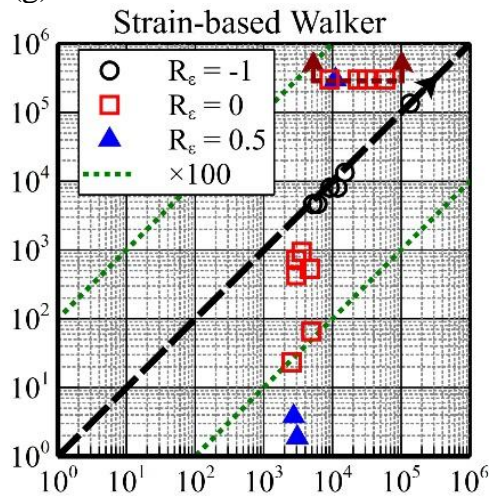

(j)

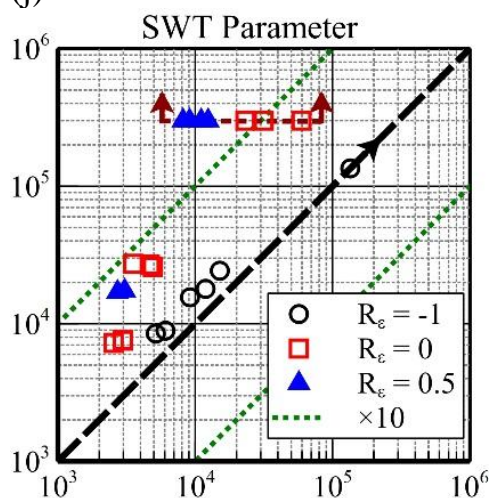

(b)

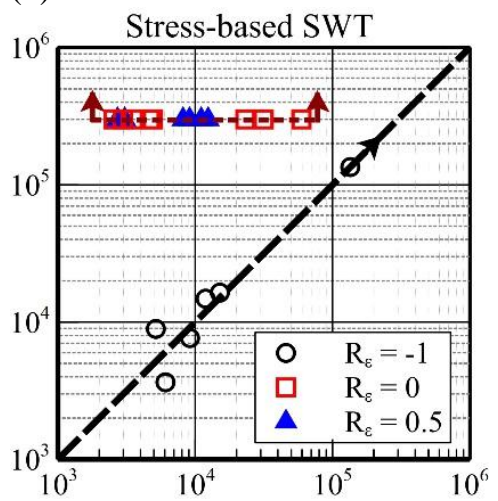

(e)

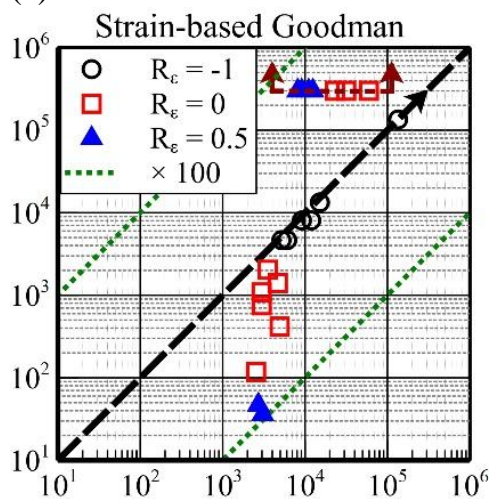

(h)

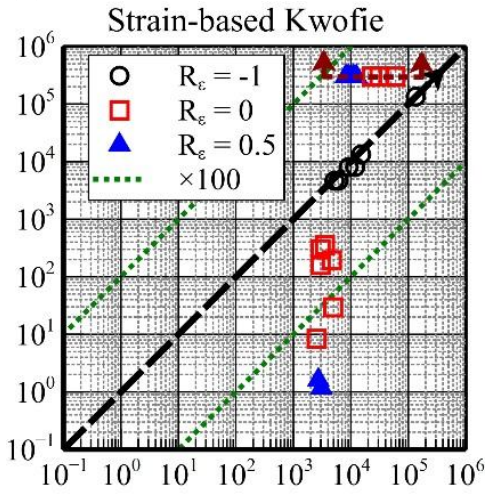

(k)

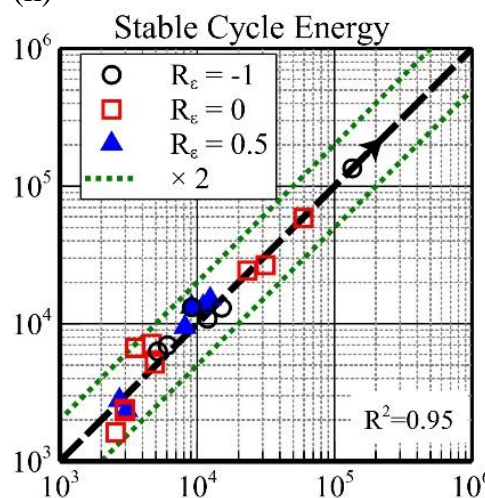

(c)

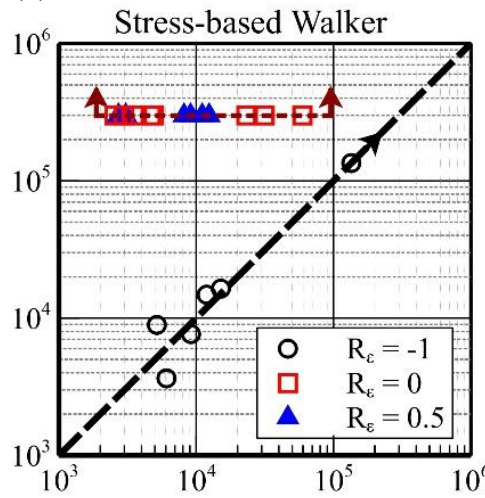

(f)

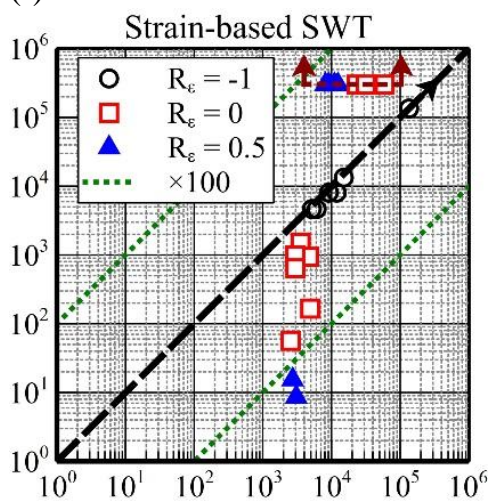

(i)

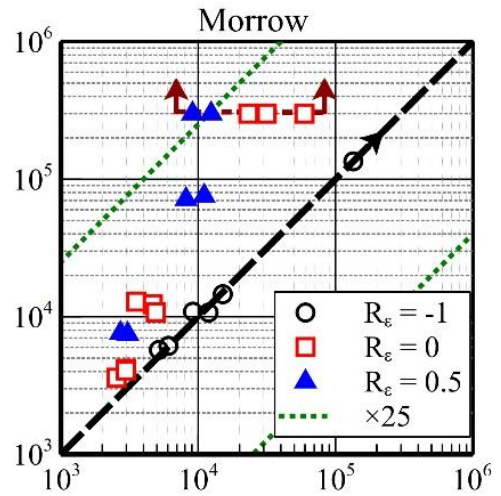

(1)

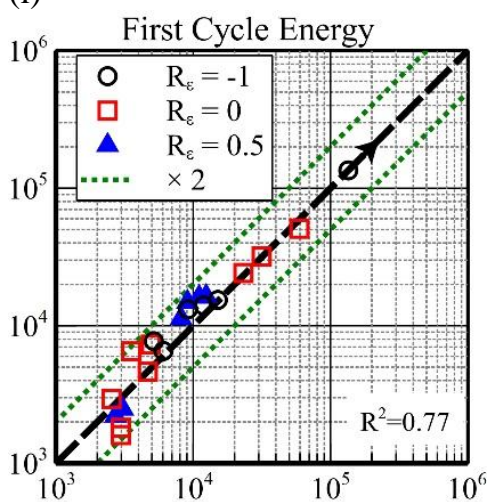

Fig. 10- Comparison of the predicted and experimental fatigue lives using (a) to (d) stress-based models, (e) to (i) strainbased models, (j) SWT parameter, (k) and (l) proposed energy-based parameter. In all the figures, the horizontal axis is the experimental number of reversals to failure and the vertical axis is the predicted number of reversals to failure. Dotted lines indicate different prediction bands. 


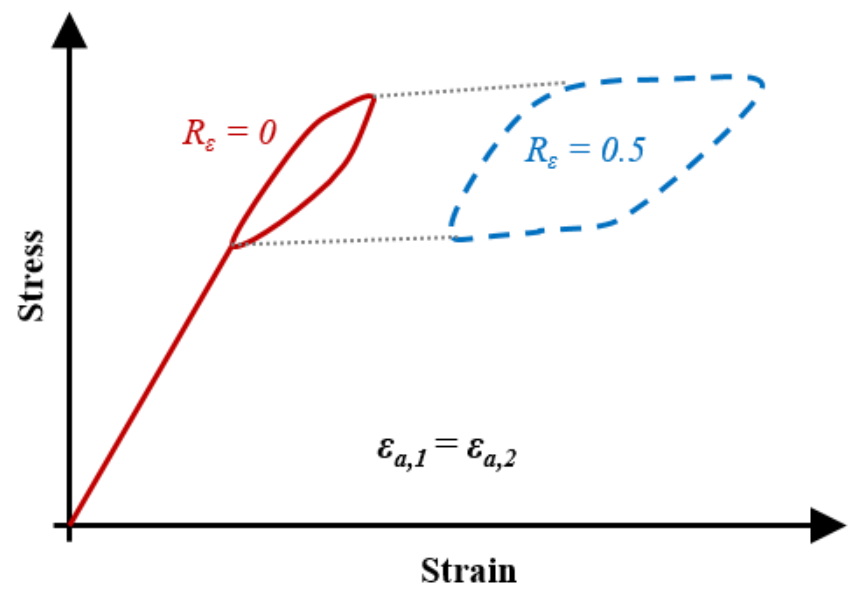

Fig. 11- Schematic representation of two tests with the same strain amplitude and different strain ratios of $R_{\varepsilon}=0$ and 0.5 . 


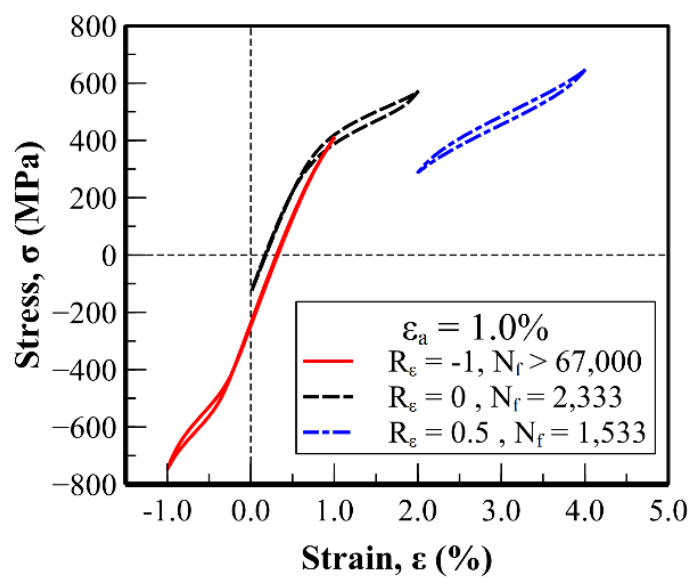

Fig. 12- Stable cycle (mid-life) hysteresis curves of three different tests with the same strain amplitude and different strain ratios 


\section{Tables}

Table 1- Mechanical properties of $\mathrm{Ni}_{50.8} \mathrm{Ti}_{49.2}$ used in this study [15]

Table 2- Details of fatigue experiments and analysis results for the investigated $\mathrm{Ni}_{50.8} \mathrm{Ti}_{49.2}$ 
Table 1- Mechanical properties of $\mathrm{Ni}_{50.8} \mathrm{Ti}_{49.2}$ used in this study [16]

\begin{tabular}{|l|c|}
\hline Property & Value \\
\hline Austenite modulus, $E_{A}(\mathrm{GPa})$ & 73 \\
\hline Stress-induced martensite modulus, $E_{M}(\mathrm{GPa})$ & 22 \\
\hline Ultimate stress, $\sigma_{u}(\mathrm{MPa})$ & 1,040 \\
\hline $\mathrm{A} \rightarrow \mathrm{M}$ start stress, $\sigma_{s}^{4 M}(\mathrm{MPa})$ & 515 \\
\hline $\mathrm{A} \rightarrow \mathrm{M}$ start strain, $\varepsilon_{s}^{A M}(\%)$ & 1.0 \\
\hline $\mathrm{A} \rightarrow \mathrm{M}$ finish strain, $\varepsilon_{s}^{A M}(\%)$ & 3.4 \\
\hline
\end{tabular}


Table 2- Details of fatigue experiments and analysis results for the investigated $\mathrm{Ni}_{50.8} \mathrm{Ti}_{49.2}$

\begin{tabular}{|c|c|c|c|c|c|c|c|c|c|}
\hline \multirow{2}{*}{$\mathrm{R}_{\varepsilon}$} & $\varepsilon_{\mathrm{a}}$ & $\varepsilon_{\mathrm{m}}$ & $2 \mathrm{~N}_{\mathrm{f}}$ & $\sigma_{\mathrm{eq}, \mathrm{G}}$ & $\sigma_{\mathrm{eq}, \mathrm{SWT}}$ & $\sigma_{\mathrm{eq}, \mathrm{W}}$ & $\sigma_{\mathrm{eq}, \mathrm{K}}$ & $\mathrm{W}_{\text {Stable }}^{\mathrm{t}}$ & $\mathrm{W}_{\text {first }}^{\mathrm{t}}$ \\
\hline & $(\%)$ & $(\%)$ & (Rev.) & $(\mathrm{MPa})$ & $(\mathrm{MPa})$ & $(\mathrm{MPa})$ & $(\mathrm{MPa})$ & $\mathrm{MJ} / \mathrm{m}^{3}$ & $\mathrm{MJ} / \mathrm{m}^{3}$ \\
\hline \multirow{6}{*}{-1} & 1.00 & 0.00 & $>134,878$ & 581 & 581 & 581 & 581 & 0.11 & 0.16 \\
\hline & 1.10 & 0.00 & 15,116 & 594 & 594 & 594 & 594 & 0.26 & 0.31 \\
\hline & 1.25 & 0.00 & 11,906 & 599 & 599 & 599 & 599 & 0.39 & 0.41 \\
\hline & 1.25 & 0.00 & 9,164 & 634 & 634 & 634 & 634 & 0.21 & 0.38 \\
\hline & 1.50 & 0.00 & 6,076 & 675 & 675 & 675 & 675 & 0.51 & 0.90 \\
\hline & 1.50 & 0.00 & 5,170 & 626 & 626 & 626 & 626 & 0.45 & 0.62 \\
\hline \multirow{9}{*}{0} & 0.40 & 0.40 & 59,392 & 268 & 304 & 331 & 331 & 0.04 & 0.06 \\
\hline & 0.50 & 0.50 & 23,212 & 339 & 362 & 387 & 418 & 0.09 & 0.15 \\
\hline & 0.50 & 0.50 & 31,516 & 264 & 303 & 335 & 337 & 0.12 & 0.06 \\
\hline & 1.00 & 1.00 & 4,666 & 437 & 441 & 464 & 526 & 0.34 & 1.09 \\
\hline & 1.00 & 1.00 & 3,542 & 456 & 458 & 477 & 536 & 0.39 & 0.76 \\
\hline & 1.00 & 1.00 & 4,920 & 371 & 385 & 417 & 472 & 0.50 & 0.60 \\
\hline & 1.50 & 1.50 & 2,542 & 394 & 403 & 434 & 501 & 1.28 & 1.43 \\
\hline & 1.50 & 1.50 & 2,978 & 488 & 486 & 502 & 563 & 1.06 & 2.32 \\
\hline & 1.50 & 1.50 & 2,974 & 509 & 506 & 519 & 573 & 1.01 & 2.13 \\
\hline \multirow{6}{*}{0.5} & 0.40 & 1.20 & 12,426 & 120 & 187 & 231 & 162 & 0.13 & 0.21 \\
\hline & 0.40 & 1.20 & 9,094 & 121 & 188 & 233 & 163 & 0.16 & 0.24 \\
\hline & 0.50 & 1.50 & 8,152 & 157 & 219 & 264 & 213 & 0.18 & 0.29 \\
\hline & 0.50 & 1.50 & 11,054 & 124 & 191 & 234 & 167 & 0.29 & 0.32 \\
\hline & 1.00 & 3.00 & 3,066 & 323 & 339 & 386 & 437 & 0.46 & 1.13 \\
\hline & 1.00 & 3.00 & 2,716 & 350 & 359 & 404 & 473 & 0.28 & 1.24 \\
\hline
\end{tabular}

